\title{
A research on bonding mechanics of butt welding joint of deformed $\mathrm{Zn}$ alloy
}

\author{
Liling Zhen ${ }^{1, a}$, Bei Tang ${ }^{2, b}$, Jianxun Fan ${ }^{1, c}$, Leyi Du ${ }^{1, d}$, Liangchao Ma ${ }^{1, e}$ \\ ${ }^{1}$ Ningbo Branch of China Academy of Ordnance Science, Ningbo 315103, China; \\ ${ }^{2}$ School of Materials Science and Engineering, Central South University, Changsha 410083, China

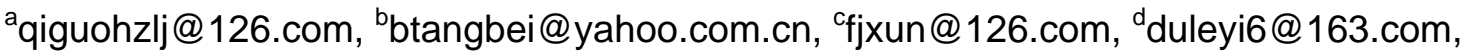 \\ emlc2014@126.com
}

Keywords: Deformed Zn alloy, Cold-pressure welding, Butt resistance welding, Plastic flow, Re-crystallization

\begin{abstract}
SEM, XRD and TEM were used to investigate the bonding mechanics of cold-pressure welding and butt resistance welding joints of deformed $\mathrm{Zn}$ alloy. Plastic flow was observed in cold-pressure welding joint. The welding seam preserved a refined microstructure. The butt resistance welding joint had obviously re-crystallized and coarsened, which was favorable to release internal stress. The substrate $\mathrm{Zn}$ alloy and cold-pressure welding joint were both composed of $\mathrm{Zn}$-rich $\eta$-phase and Al-rich $\alpha$-phase. Butt resistance welding joint was primarily composed of $\eta$-phase, granular $\alpha$-phase, $\alpha+\eta$ phases with lamellar structures and dispersive $\mathrm{CuZn} 4$ precipitation.
\end{abstract}

\section{Introduction}

Drawing $\mathrm{Zn}$ alloys are generally $\mathrm{Zn}-\mathrm{Al}$ alloys. To obtain the bar or wire, the process methods in the world include: continuous metal cast process, hot extrusion, drawing and coil rod, etc. It is widely used in hot spraying, welding material and making nail, screw, net and so on(Refs.1-4). Because its intrinsic microstructure inhomogeneity usually leads to fracture in the process of drawing, appropriate conjunction technology is needed. Cold-pressure welding and butt resistance welding are two conjunction methods with high efficiency and low cost, which is applicable for wire stock $\mathrm{Zn}$ alloy. In productive practice, both of them can attain high strength, while the cold-pressure welding joint relatively crack much in the subsequent drawing process. In this research, microstructure analysis of joints obtained by the two methods were carried out on SEM, $\mathrm{XRD}$ and TEM in the hope of revealing the bonding mechanics and its effect on drawing process and providing theoretical instructions in practical production.

\section{Experiment}

$\mathrm{Zn}-\mathrm{Al}$ alloy bar of $\varphi 8 \mathrm{~mm}$ was used as the base metal in this research. And its composition is shown in table 1.

\begin{tabular}{cccc}
\hline \multicolumn{4}{c}{ Table $1-$ Chemical composition of zinc alloy (wt-\%) } \\
$\mathrm{Al}$ & $\mathrm{Cu}$ & $\mathrm{Mg}$ & $\mathrm{Zn}$ \\
$9-10$ & $0.6-1.0$ & $0.02-0.05$ & $\mathrm{Bal}$. \\
\hline
\end{tabular}

UN-25 butt welder and cold-pressure welder were used. Microstructure and fracture analysis were carried out on QUANTA-FEG2500 SEM and Tecnai G $^{2}$ 20ST TEM.

\section{Results and Discussion}

SEM patterns of cold-pressure welding joint and butt resistance welding joint are shown in Fig.1.Plastic flow was observed in the cold-pressure welding joint. Phases in the base metal were distorted to streamlines distribution,as shown in Fig1a,b. 

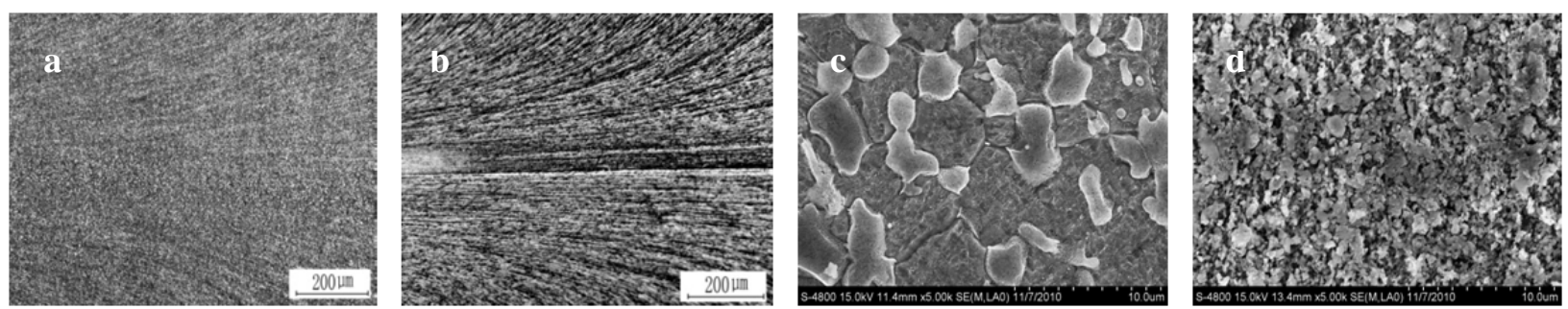

Fig.1-Microstructures of joints

a,c_-butt resistance welding; b,d — cold-pressure welding

It is obvious that butt resistance welding joint has re-crystallized and coarsened as shown in Fig1c. Such microstructure can improve the joints' plasticity and make the wire pass the mould much easier because re-crystallization is favorable to release the internal stress which is always an important factor on assessing the welding performance(Refs.5-8). The cold-pressure welding joint preserves a refined microstructure. There is no visible re-crystallization detected, but mechanical impurity of finely crushed grains. In the drawing procedure, the internal stress may further expand because of inhomogeneous deformation. Therefore, the cold-pressure welding joint tends to generate more cracks which eventually lead to fracture in the subsequent drawing process.

Compared with cold-pressure welding joint, butt resistance welding joint is subjected to much lower deformation amount, which results in lower hardness. The differences of microstructure between them give certain effect on both welding process and post treatment. To improve weldability and to optimize the production technology, annealing after welding operation to eliminate micro internal stress becomes a necessity, especially to cold-pressure welding joint.

XRD testing results of the joints' interface are shown in Fig.2 and Fig.3 respectively. It shows that the base metal is basically composed of Zn-rich $\eta$-phase and Al-rich $\alpha$-phase. No new phase occurred in the joints during both welding operations. In butt resistance welding joint, the peak intensity of diffraction apparently decreased when $2 \theta$ equals $36.4^{\circ}$, which means solid solubility of $\mathrm{Zn}$ in Al has been improved under certain heat treatment. Peak intensity of $\alpha$-phase also decreased, which means more $\mathrm{Al}$ atoms have entered the $\eta-\mathrm{Zn}$ phase. In general, the heating process of butt

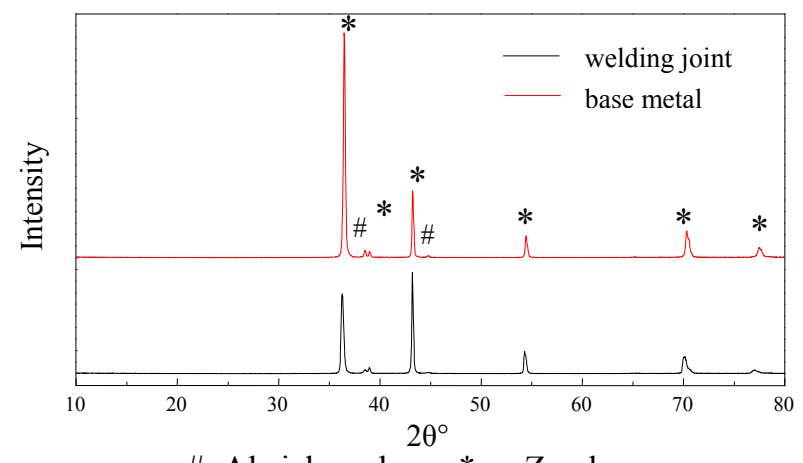

\#: Al-rich $\alpha$-phase; *: $\eta$-Zn phase

Fig.2-XRD analysis of base metal and butt resistance welding joint

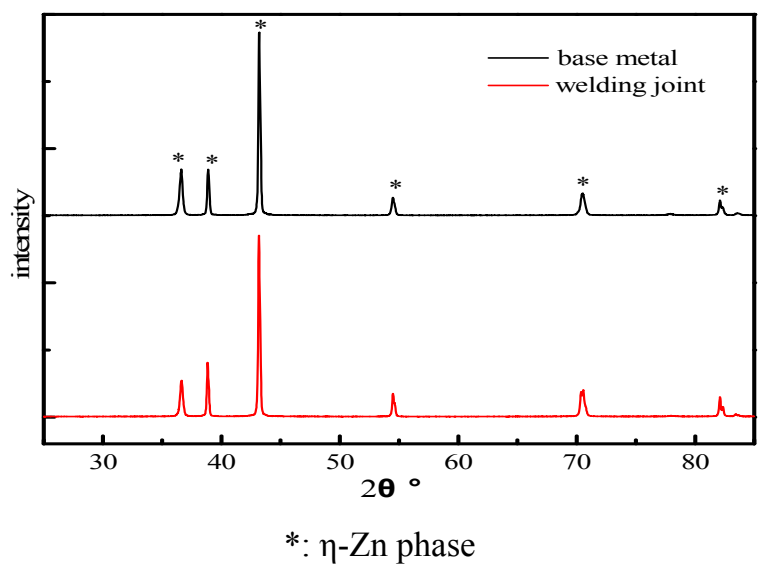

Fig.3 - XRD analysis of base metal and cold-pressure welding joint 
resistance welding may be the critical factor which has apparently changed the solid solubility of $\mathrm{Zn}$ in $\mathrm{Al}$ and microstructure of the joint. It is further proved in TEM analysis.

TEM analysis of butt resistance welding joint and cold-pressure welding joint are shown in Fig.4.The substrate $\mathrm{Zn}$ alloy is characterized to be of binary phase structure (see Fig.4a). In the inter-space of black phase, there is white phase (arrow 1) with small black phases inside. The black area (arrow 2) is identified to be Zn-rich $\eta$-phase by EDS, while the white one is Al-rich $\alpha$-phase. Plastic $\alpha$-phase is enclosed by Zn-rich $\eta$-phase (see Fig 4c).
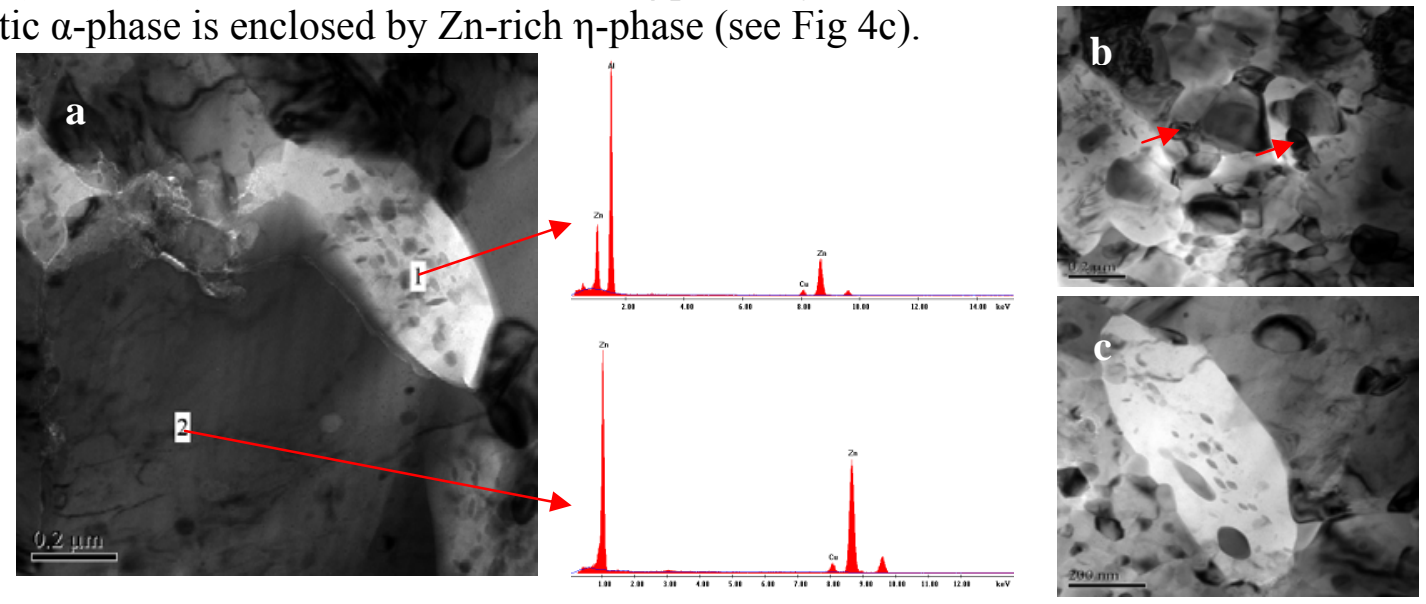

Fig.4-TEM patterns and EDS analysis of base metal

Fig. 5 shows the TEM patterns of butt resistance welding joint.There is a small amount of eutectic phases composed of $\alpha+\eta$ phase with lamellar structures in butt resistance welding joint (Fig.5a). It implies that the welding temperature is high enough to melt the core of the joint, which makes $\mathrm{Zn}$ and $\mathrm{Al}$ further dissolve into each other and form $\beta(\mathrm{ZnAl})$ phase. In the cooling process, the $\beta$ ( $\mathrm{ZnAl})$ phase decomposes into $\alpha+\eta$ phase through a eutectic reaction. Except for $\alpha+\eta$ phases, $\alpha$-phase also shows quite different characteristic compared with that in base metal. The granular $\alpha$-phase exhibits a streamline distribution (Fig.5b).

It is worth noticing that there are dispersive phases precipitated in $\alpha$-phase and $\eta$-phase (Fig5b, c). Diffraction pattern (Fig.5d) shows that the precipitation is CuZn4. For the heating process further dissolved $\mathrm{Al}$ into $\mathrm{Zn}$, the solid solubility of $\mathrm{Cu}$ in $\eta$-phase changes. In the cooling process, more $\mathrm{Cu}$ precipitated in the form of $\mathrm{CuZn} 4$. The intermediate compound $\mathrm{CuZn} 4$ is of close-packed hexagonal structure. Its hardness is higher than $\eta-Z n$ phase's. The solution strengthening of Al in $\mathrm{Zn}$ and the dispersion strengthening of $\mathrm{CuZn} 4$ precipitation effectively improves the mechanical properties of butt resistance welding joint. Improvement in plasticity makes it much easier for the wire to pass the mould.
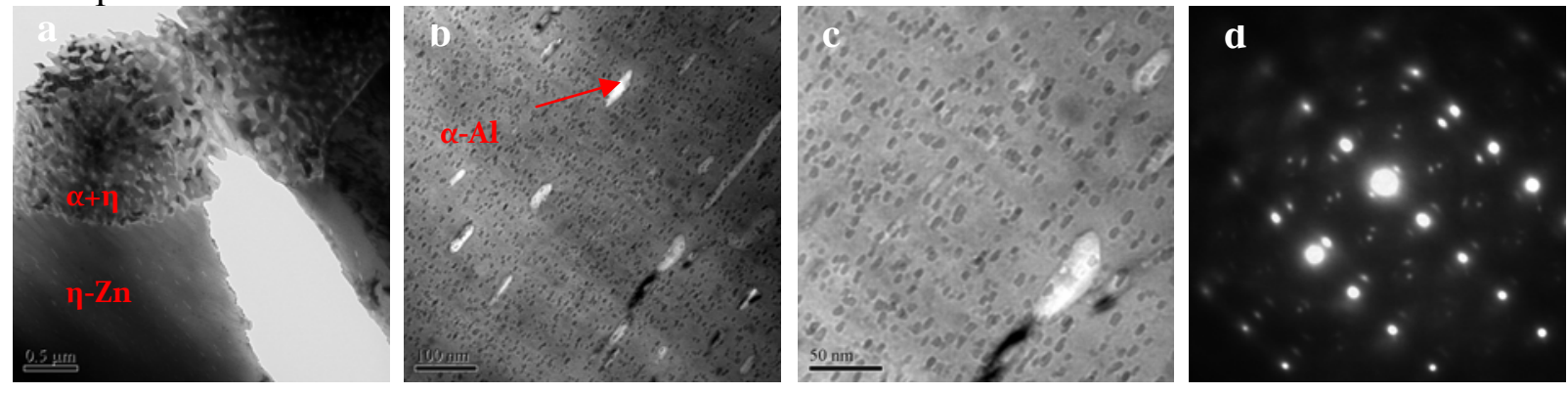

Fig.5-TEM patterns of butt resistance welding joint

Fig. 6 shows the TEM patterns of cold-pressure welding joint.Apparent structural changes are observed in Al-rich $\alpha$-phase. The Al-rich $\alpha$-phase in the base metal is of big granular shape and distributed randomly. While the Al-rich $\alpha$-phase in cold-pressure welding joint is of rice grain shape and distributed like a ribbon that is parallel to welding seam(Fig 6a,b). It means plastic flow has occurred, which is coincident with that observed in Figlb. No bulk $\eta$-Zn phase is observed in the welding joint but fine $\eta-Z n$ phase (Fig $6 c, d$ ), which is quite different with that in base metal shown in Fig4b. The former has a grain size of $100 \sim 200 \mathrm{~nm}$, while the latter 200 300nm. Therefore, the 
welding joint can attain a higher strength than the base metal because of finer $\eta-\mathrm{Zn}$ phase and more homogeneous microstructure.
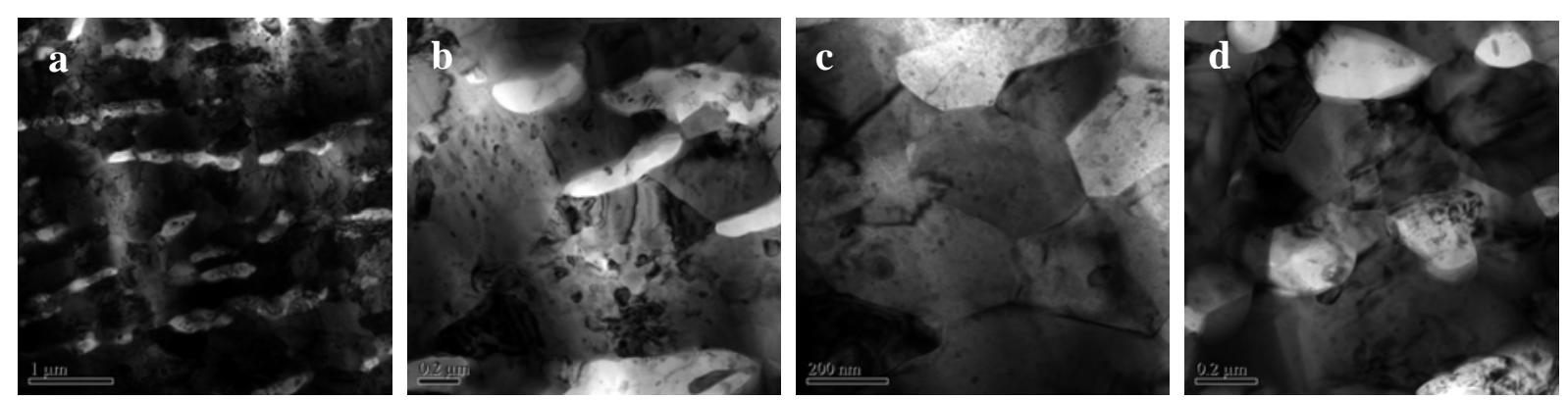

Fig.6-TEM patterns of cold-pressure welding joint

$\mathrm{a}, \mathrm{b}$-welding seam;c,d-base metal

\section{Conclusions}

Welding joints have been made by cold-pressure and butt resistance welding processes. The major conclusions of this study can be summarized as follows:

1. Plastic flow was observed in the cold-pressure welding joint. Bulk phases refined completely. No new phases occurred in cold-pressure welding joint. The butt resistance welding joint had obviously re-crystallized and coarsened, which was favorable to release the internal stress. Such microstructure could assure the joint excellent plasticity and make the wire pass the mould much easier in the subsequent drawing process.

2.The substrate $\mathrm{Zn}$ alloy was composed of $\mathrm{Zn}$-rich $\eta$-phase and Al-rich $\alpha$-phase. So was the cold-pressure welding joint. Butt resistance welding joint was primarily composed of $\eta$-Zn phase, granular $\alpha$-Al phase, $\alpha+\eta$ phases with lamellar structures and dispersive $\mathrm{CuZn} 4$ precipitated in welding seam area. Changes in microstructure contributed a lot to the mechanical properties of the butt resistance welding joint. The strength and elongation percentage rise because of solution strengthening and dispersion strengthening.

3.Annealing mechanics of cold-pressure welding joint of $\mathrm{Zn}$ alloy need a further investigation.

\section{Acknowledgements}

This research is sponsored by National Key Technology R\&D Program of the Ministry of Science and Technology (2009BAE71B05) and Ningbo Natural Science Foundation (2012A610058).

\section{References}

[1] Pantazopoulos G, A. Sampani:J Fail Anal Prevent. Vol.5 (2005), p.6.

[2] Durman M,Murphy S:Mater.Sci.1997,p.1603.

[3] Diot M, Philippe MJ, WeGria J, Esling C: Script Mater. Vol. 40 (1999), p. 1295.

[4] G. Pantazopoulos , A. Sampani: Eng.Fail.Anal.14 (2007),p.642.

[5] YT Li,Z Y Du,C Y Ma: Journal of Tianjing Univeristy.Vol.35 (2002), p.100.

[6] Lu L, Lai M O, Zhang S:J. Mater.Proc.Tech. Vol.67 (1997), p. 100.

[7] H U Jing, Gonser J, Gleiter H:Solid State Commun. Vol.76 (1990), p. 197.

[8] C X Chen: Journal of Hebei Industry University.(1999). 